\title{
Article \\ A Bootstrap Structure Directly Charged by BUS Voltage with Threshold-Based Digital Control for High-Speed Buck Converter
}

\author{
Yujie Guo ${ }^{1,2}$, Fang Yuan ${ }^{1}$, Yukuan Chang ${ }^{1,2}$, Yuxia Kou ${ }^{1,2}$ and Xu Zhang ${ }^{1, *}$ \\ 1 State Key Laboratory on Integrated Optoelectronics, Institute of Semiconductors, Chinese Academy of \\ Sciences, Beijing 100083, China; guoyujie17@semi.ac.cn (Y.G.); yuanfang@semi.ac.cn (F.Y.); \\ changyukuan@semi.ac.cn (Y.C.); kouyuxia@semi.ac.cn (Y.K.) \\ 2 University of Chinese Academy of Sciences, Beijing 100049, China \\ * Correspondence: zhangxu@semi.ac.cn
}

check for updates

Citation: Guo, Y.; Yuan, F.; Chang, Y.; Kou, Y.; Zhang, X. A Bootstrap Structure Directly Charged by BUS

Voltage with Threshold-Based Digital Control for High-Speed Buck Converter. Electronics 2021, 10, 2863. https://doi.org/10.3390/ electronics10222863

Academic Editors: Yuh-Shyan Hwang and San-Fu Wang

Received: 13 October 2021

Accepted: 16 November 2021

Published: 20 November 2021

Publisher's Note: MDPI stays neutral with regard to jurisdictional claims in published maps and institutional affiliations.

Copyright: (c) 2021 by the authors. Licensee MDPI, Basel, Switzerland. This article is an open access article distributed under the terms and conditions of the Creative Commons Attribution (CC BY) license (https:// creativecommons.org/licenses/by/ $4.0 /)$.

\begin{abstract}
This article proposes a high-frequency, area-efficient high-side bootstrap circuit with threshold-based digital control (TBDC) that is directly charged by BUS voltage (DCBV). In the circuit, the voltage of the bootstrap is directly obtained from the BUS voltage instead of the on-chip low dropout regulator (LDO), which is more suitable for a high operating frequency. An area-efficient threshold-based digital control structure is used to detect the bootstrap voltage, thereby effectively preventing bootstrap under-voltage or over-voltage that may result in insufficient driving capability, increased loss, or breakdown of the power device. The design and implementation of the circuit are based on CSMC $0.25 \mu \mathrm{m} 60 \mathrm{~V}$ BCD technology, with an overall chip area of $1.4 \times 1.3 \mathrm{~mm}^{2}$, of which the bootstrap area is $0.149 \mathrm{~mm}^{2}$ and the figure-of-merit (FOM) is 0.074 . The experimental results suggest that the bootstrap circuit can normally operate at $5 \mathrm{MHz}$ with a maximum buck converter efficiency of $83.6 \%$. This work plays a vital role in promoting the development of a wide range of new products and new technologies, such as integrated power supplies, new energy vehicles, and data storage centers.
\end{abstract}

Keywords: bootstrap circuit; high voltage; buck converter; high frequency; area-efficient

\section{Introduction}

With the continuous development of modern electronic equipment power supplies, miniaturized and high-performance power drivers have become a current research hotspot [1-6]. Regarding traditional silicon complementary metal-oxide-semiconductor (CMOS) technology, NMOS (n-channel metal-oxide-semiconductor) is usually selected as the power device [7-9], which is mainly attributed to its high carrier mobility and desirable device area [10]. Additionally, third-generation semiconductor power devices with the characteristics of high speed and low on-resistance, such as GaN HEMTs (gallium nitride high-electron-mobility transistors) [11-14], are also dominated by N-type devices.

LDOs [15], dc-dc converters (such as charge pumps [16-18]) and pre-regulators [19] are mainly employed in a low-side N-Type power MOS structure with the power supply relative to ground. Regarding a high-side N-type power device, the floating source demonstrates the high-side driving problem of the device $[20,21]$, which is usually solved by bootstrap charging circuits [22-24]. The principle of these circuits is to provide a voltage that is relative to the floating source, namely the switching node $\left(V_{\mathrm{SW}}\right)$, for driver and power MOS [25]. Although the traditional bootstrap charging circuit shown in Figure 1 has a simple structure, there are still a series of problems to be solved.

The traditional bootstrap charging circuit needs a fixed charging voltage $V_{\mathrm{DD}}$, which is generally set between 5 and $6 \mathrm{~V}$, and it is generated by the on-chip power supply. In the case of a large driving capability and high switching frequency, the requirements for 
the load current, bandwidth, and stability of the on-chip regulator are relatively high, which increases the design difficulty of the LDO. On the other hand, the change in the $V_{\text {DD }}$ will cause a certain offset in the $V_{\text {boot }}$ voltage of the traditional bootstrap circuit. When the bootstrap voltage is too high, the gate of the power device, especially the GaN HEMT, easily breaks down. Conversely, a bootstrap voltage that is too low will affect the driving capability of the circuit, resulting in excessive on-resistance of the power device and increasing power loss. Li, S.T. et al., proposed the theory of active bootstrap control $(\mathrm{ABC})$ [26], that is, the logic control of the high-side signal, low-side signal, and dead time ensures that the bootstrap capacitor is charged only when the low-side power device is turned on. Ke, X. et al., proposed an active BST balancing (ABB) method to achieve bootstrap voltage control [27].

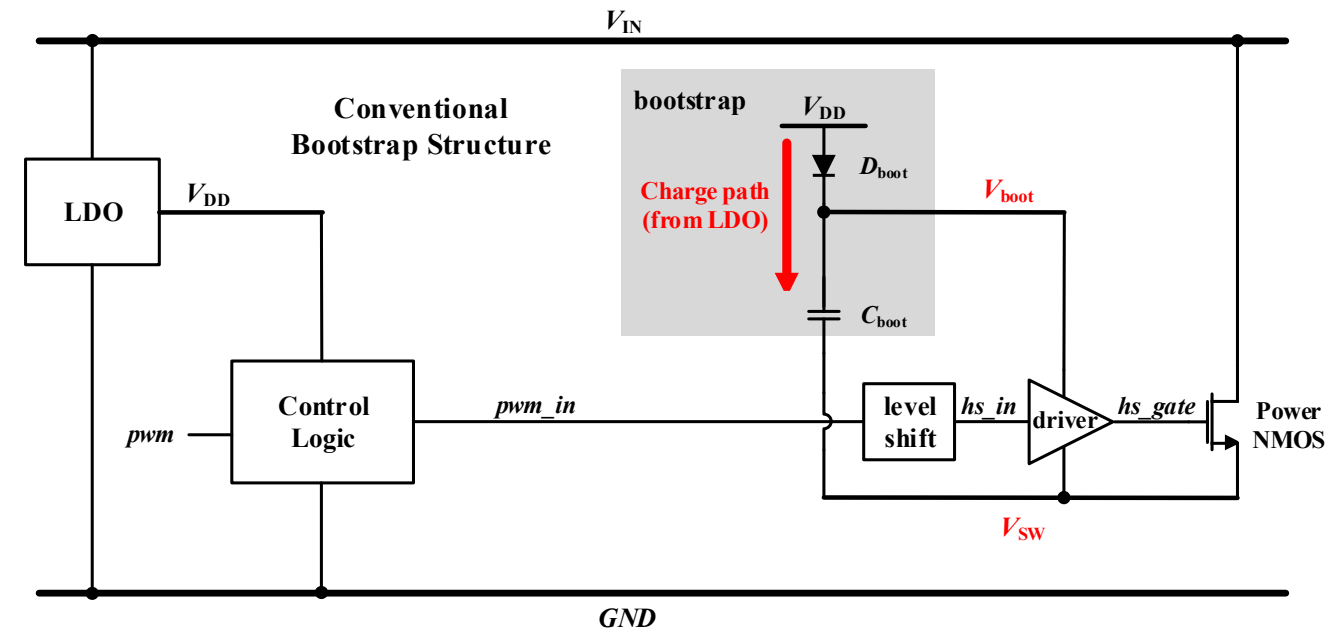

Figure 1. Traditional bootstrap structure charging from an LDO, which brings bandwidth and stability pressure to LDO.

Although a series of considerable research results have been achieved in bootstrap voltage control, there are still certain challenges in reducing the pressure on LDO design. Ming, X. et al., proposed an advanced bootstrap circuit structure that does not depend on the voltage of the on-chip low dropout linear regulator, which also ensures the stability of the high-side power rail by using the directly sensed bootstrap voltage (DSBV) [28]. A bootstrap structure is proposed by Liu, Y. et al., the bootstrap voltage of which is charged by input power and regulated by a feedback loop [29]. The conventional structure employs an analog feedback loop, the speed of which is influenced by the loop bandwidth, while high bandwidth and high stability are hard to achieve at the same time. Herein, based on the above-mentioned research, this paper presents a bootstrap circuit structure with the following advantages: a small area, high frequency, and good figure-of-merit (FOM). Without an analog loop, the speed of the structure is only determined by the thresholdbased detection circuit, avoiding the trade-off between bandwidth and stability. The DCBV circuit is used to directly charge the bootstrap capacitor from the BUS voltage $V_{\mathrm{IN}}$, which greatly reduces the design difficulty of the low dropout linear regulator. The TBDC circuit is used to detect the voltage of the high-side bootstrap power rail, which can control the on-off of the PMOS switch in the DCBV circuit, thereby ensuring that the bootstrap voltage is within the required range.

\section{Materials and Methods}

\subsection{Concept of the Proposed Bootstrap Architecture}

As shown in Figure 2, the DCBV is directly used in the bootstrap charging of the proposed structure, which reduces the pressure on the bandwidth and load capacity of the on-chip LDO at high frequency. The TBDC circuit is used to detect the bootstrap voltage, which is mainly composed of isolated MOSFETs instead of high-voltage devices, and 
controls the charging path of the bootstrap. Moreover, the logic control module is related to the detection result of the TBDC.

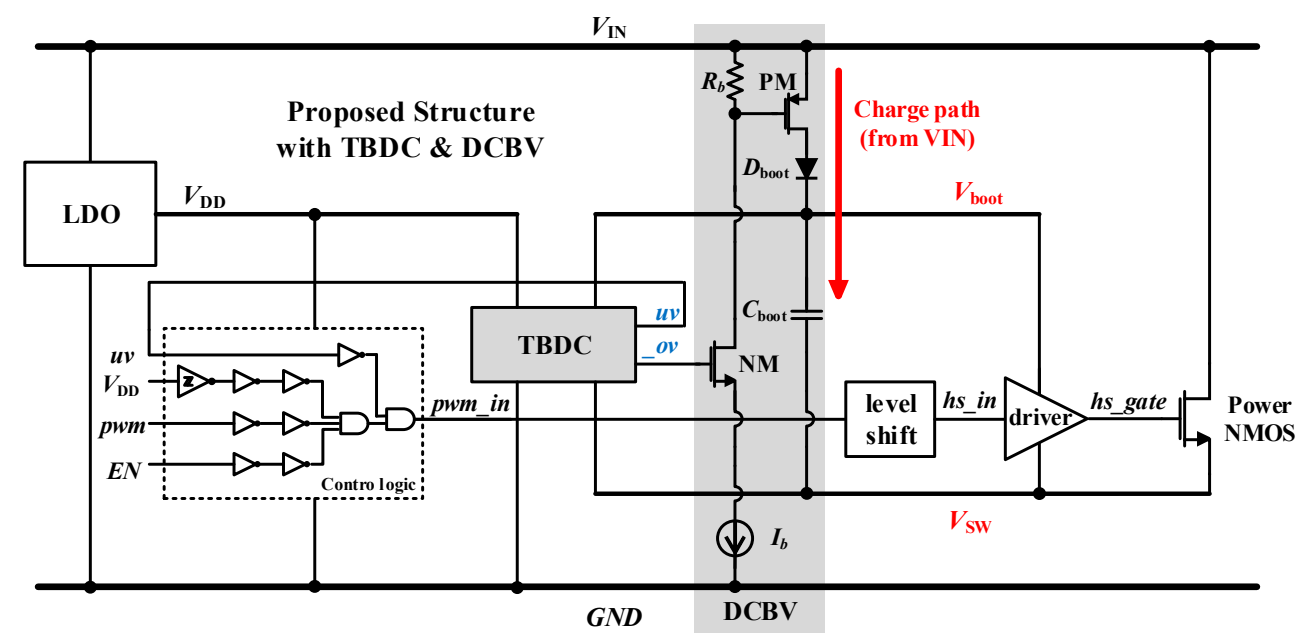

Figure 2. Proposed bootstrap structure with TBDC and DCBV.

When the TBDC detects that the bootstrap voltage is lower than the under-voltage threshold $V_{\mathrm{THL}}$, the under-voltage signal $u v$ will pull down the driving signal in the control logic circuit to turn off the power device, thereby avoiding the efficiency loss caused by insufficient driving voltage.

When the TBDC detects that the bootstrap voltage exceeds the over-voltage threshold $V_{\mathrm{THH}}$, the non-over-voltage signal_ov is set to 0 , and the gate of the PMOS switch (PM) is pulled up to $\mathrm{V}_{\mathrm{IN}}$ by the bias resistor $R_{\mathrm{b}}$, resulting in the shutdown of PM and charging path. Moreover, the bootstrap voltage slowly decreases until the TBDC detects that the bootstrap is lower than the over-voltage threshold $V_{\mathrm{THH}}$. Additionally, the _ov signal remains high The high-voltage NMOS (NM) is turned on, and the bias current $I_{\mathrm{b}}$ causes a voltage drop on the bias resistor $R_{\mathrm{b}}$. Next, the PM is turned on, and the BUS voltage $V_{\mathrm{IN}}$ charges the bootstrap capacitor $C_{\text {boot }}$ through the bootstrap diode $D_{\text {boot }}$. The charging path is shown as a red arrow, and the bootstrap voltage increases immediately. The above processes are repeated during normal operation. Due to a slight delay in the DCBV circuit, the bootstrap voltage is controlled within a voltage range with a small ripple $\left(V_{\mathrm{THH}} \pm \Delta V\right)$.

In the case of high-frequency operation, the traditional structure has relatively high requirements for the bandwidth and load regulation rate of the LDO. However, the structure designed in this work does not rely on an LDO power supply, which is more suitable for higher frequency.

The working sequence of this circuit is shown in Figure 3.

\subsubsection{Power on (Under-Voltage)}

When the BUS voltage $V_{\text {IN }}$ is powered on, the LDO starts to work, and then the low-voltage power supply $V_{\mathrm{DD}}$ increases to $5 \mathrm{~V}$ as shown in Figure 3, status (1). The enable signal EN then turns from low to high. At this time, the external input signal pwm is low. The high-side power NMOS remains off, and the switch node $V_{\mathrm{SW}}$ is 0 . Moreover, the bootstrap voltage is lower than the under-voltage threshold $V_{\mathrm{THL}}$, and the under-voltage signal $u v$ is the $V_{\mathrm{DD}}$. The $u v$ signal turns off the high-side $\mathrm{N}$-type power device in the control logic circuit.

The _ov signal is also the $V_{\mathrm{DD}}$, so the bootstrap charging path is opened, and the bootstrap voltage increases. 


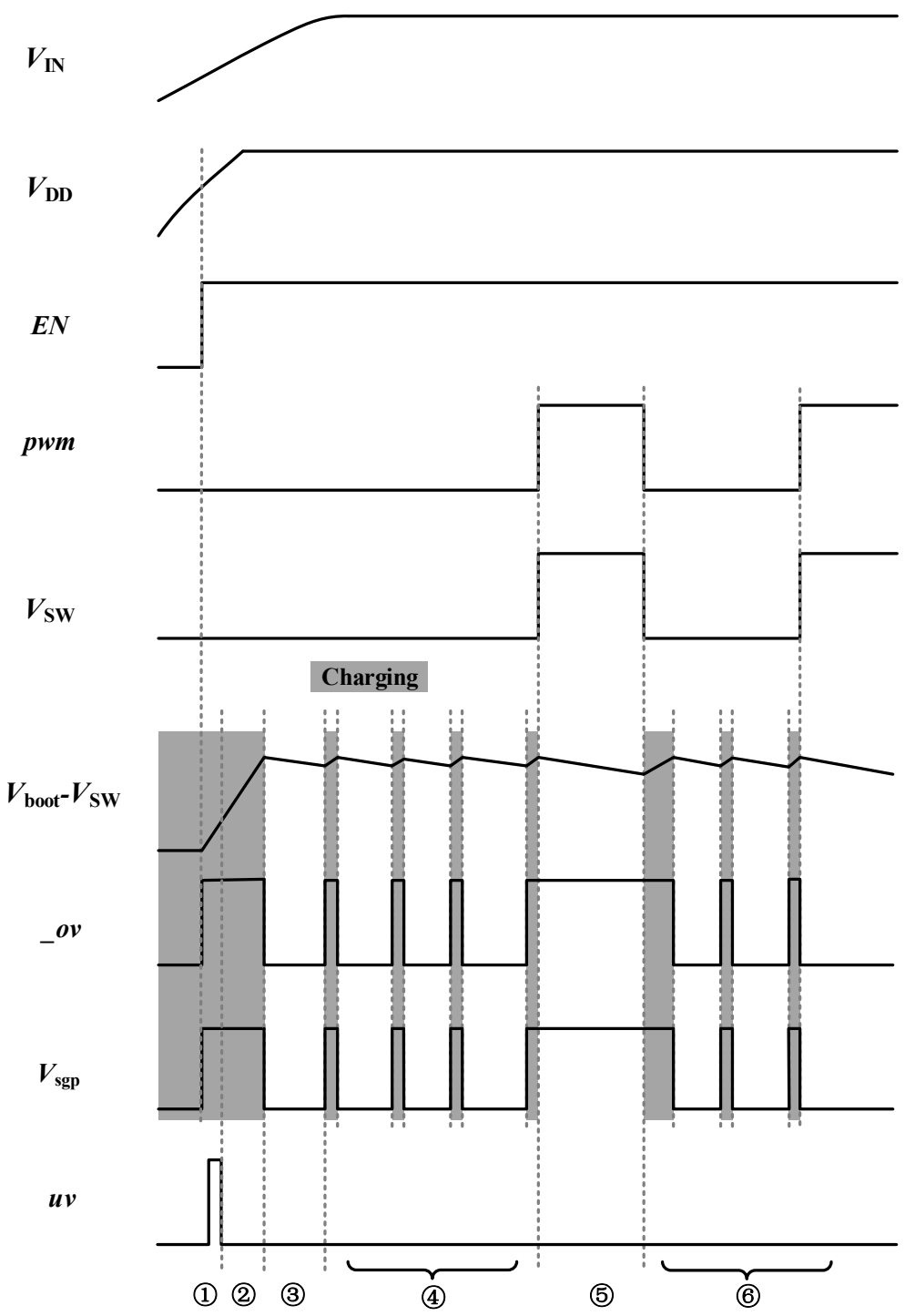

Figure 3. Working sequence of the proposed bootstrap structure.

\subsubsection{Charging}

When the bootstrap voltage increases to the under-voltage threshold $V_{\mathrm{THL}}$ as shown in Figure 3, status (2), the under-voltage signal $u v$ reverses from the $V_{\mathrm{DD}}$ to the GND, and the pwm signal can normally control the high-side power NMOS.

Additionally, the _ov signal is still the $V_{\mathrm{DD}}$, and the bootstrap charging path remains open, causing the bootstrap voltage to continue increasing.

\subsubsection{Discharging (Over-Voltage)}

When the bootstrap voltage exceeds the over-voltage threshold $V_{\mathrm{THH}}$ as shown in Figure 3, status (3), the _ov signal is flipped from the $V_{\mathrm{DD}}$ to the GND. Therefore, the charging path is turned off, and the bootstrap voltage slowly decreases.

\subsubsection{Repeating (pwm Remains Low)}

When the external input signal pwm continues to be low and the bootstrap voltage decreases to less than the over-voltage threshold $V_{\text {THH }}$ as shown in Figure 3, status (4), processes Charging (status (2) and Discharging (status (3)) are repeated. 


\subsection{5. pwm Becoming High}

When the external input signal pwm becomes high, the high-side power NMOS is turned on, and the switch node $V_{\mathrm{SW}}$ voltage is pulled up to the BUS voltage $V_{\mathrm{IN}}$ as shown in Figure 3, status (5). At this time, since the voltage at the anode of the bootstrap diode $D_{\text {boot }}$ is the BUS voltage $V_{\text {IN }}$ and the voltage at the negative terminal of $D_{\text {boot }}$ is the high-side bootstrap power rail voltage $V_{\text {boot }}$, the charging path cannot be charged. Additionally, the high-side bootstrap power rail slowly decreases due to the power supply to the high-side driver and the leakage of the bootstrap capacitor $C_{\text {boot }}$.

\subsection{6. pwm Becoming Low}

As status (6) shows in Figure 3, after the input signal pwm becomes low, processes Charging and Discharging are repeated, which behaves the same as status (4).

\subsection{Circuit Realization}

The TBDC circuit is used to detect the over-voltage and under-voltage conditions of the bootstrap voltage, which is composed of three parts as shown in Figure 4, including a current bias and start-up circuit, an under-voltage detection circuit, and an over-voltage detection circuit. In addition, level shifter and driver are shown in Figures 5 and 6, respectively.

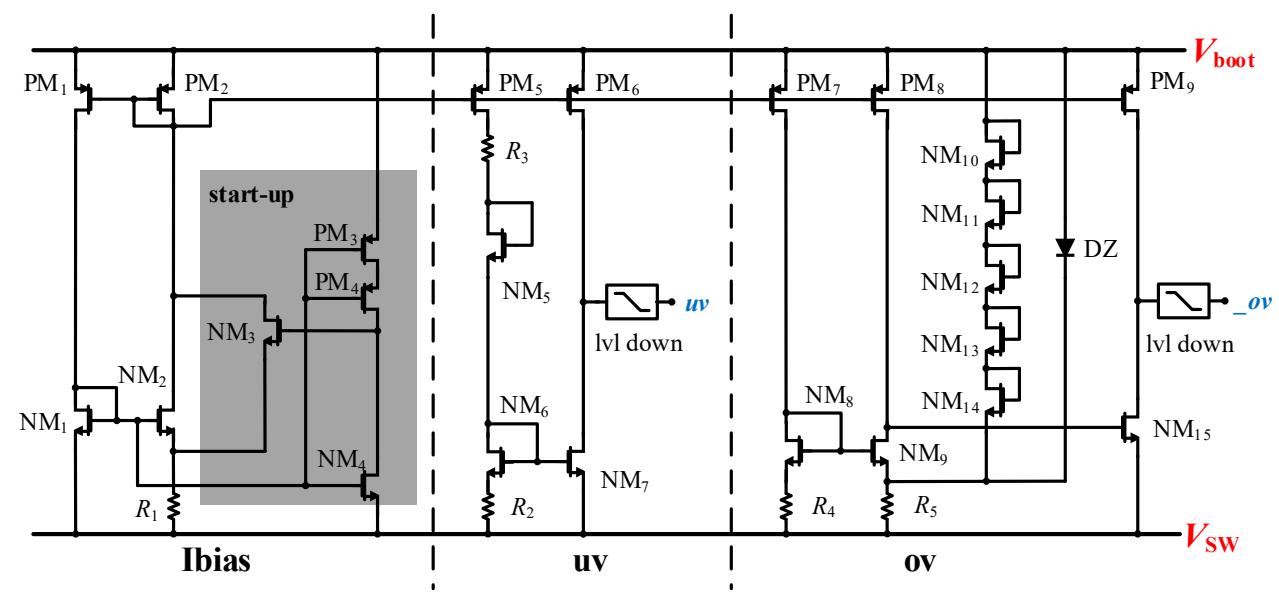

Figure 4. Circuit realization of the proposed TBDC with fully isolated devices.

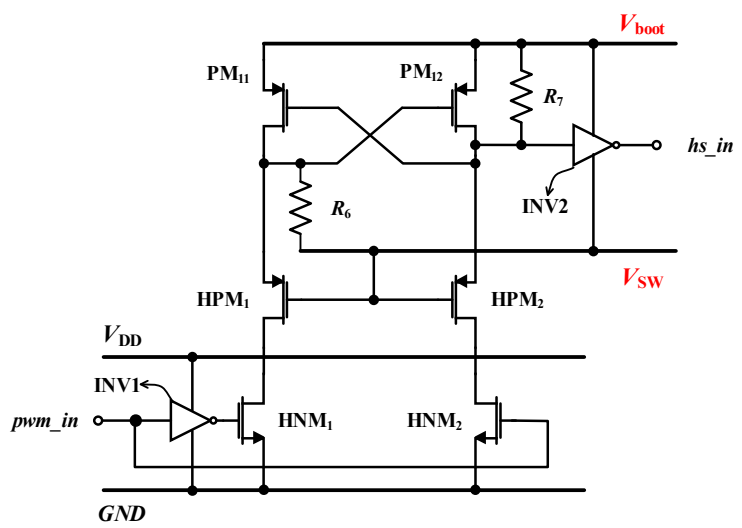

(a)

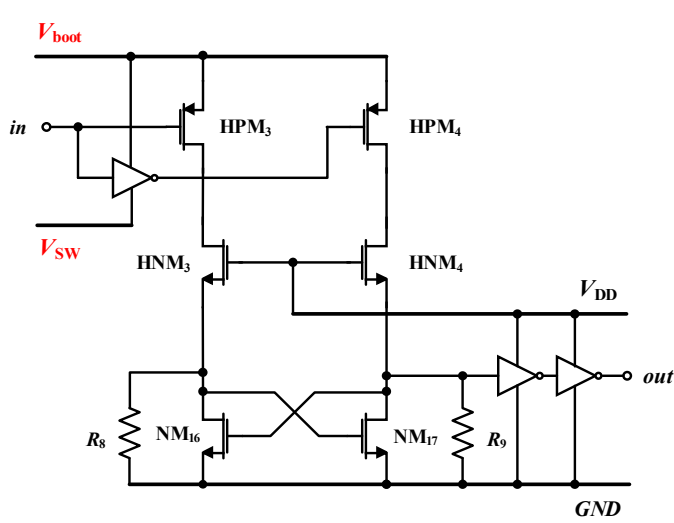

(b)

Figure 5. Circuit realization of (a) level-up shifter and (b) level-down shifter employed in proposed structure. 


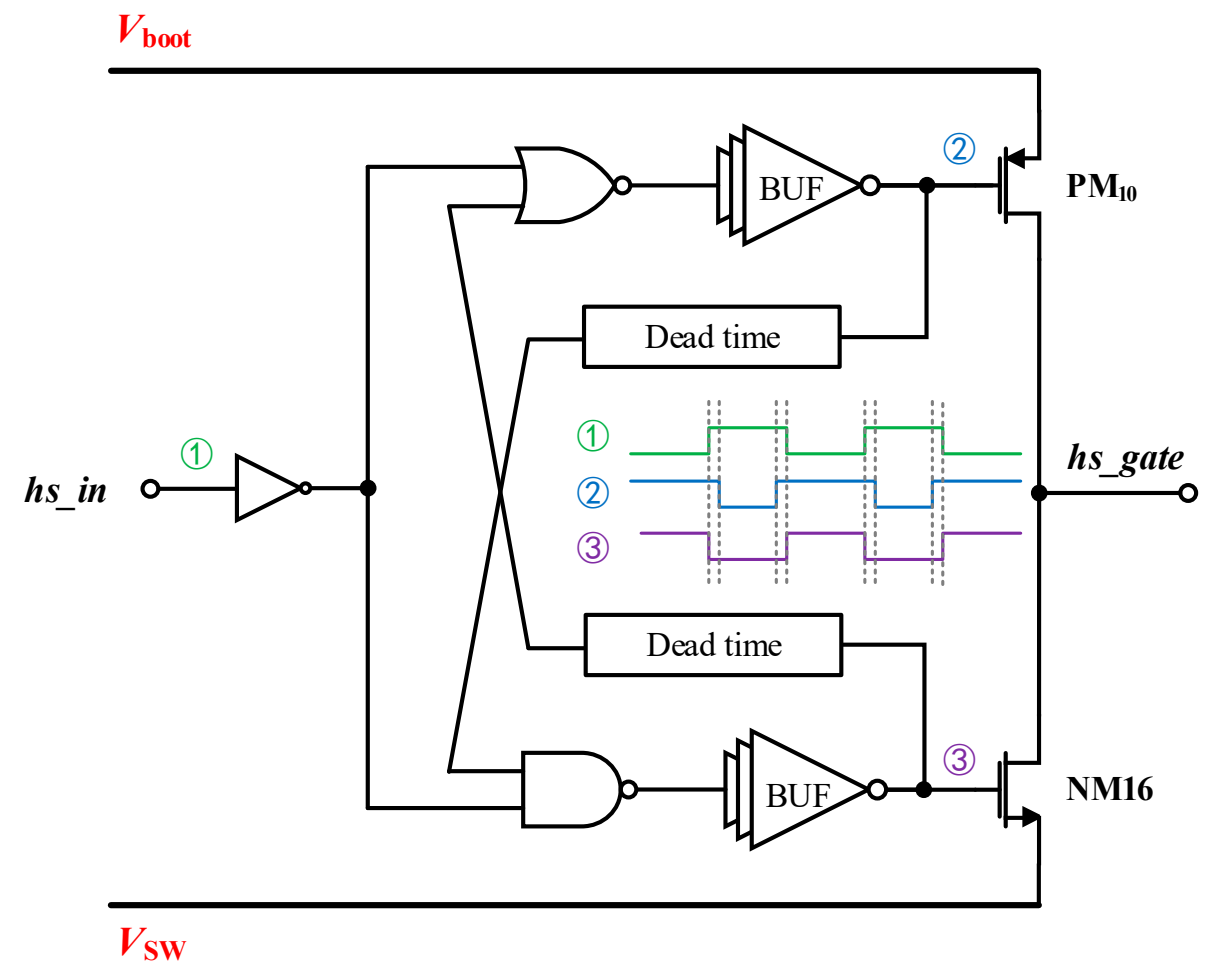

Figure 6. Circuit realization of driver and waveforms of $h$ s_in, gate of $\mathrm{PM}_{10}$ and $\mathrm{NM}_{16}$.

\subsubsection{TBDC Circuit}

\section{- Current bias and start-up circuit}

The current bias and start-up circuit are shown in the left part in Figure 4, which are composed of isolated PMOS $\mathrm{PM}_{1}-\mathrm{PM}_{2}$, isolated NMOS $\mathrm{NM}_{1}-\mathrm{NM}_{2}$, and a resistor $R_{1}$. $\mathrm{PM}_{1}$ mirrors the current of $\mathrm{PM}_{2}$, and resistor $R_{1}$ is used to control the magnitude of the bias current. The bias current increases as the bootstrap voltage increases until it stabilizes. The stable bias current is [30]:

$$
I_{\text {out }}=\frac{2}{\mu_{n} C_{o x}(W / L)_{1}} \times \frac{1}{R_{1}^{2}} \times\left(1-\frac{1}{\sqrt{K}}\right)^{2}
$$

where $\mu_{n}$ is the electron mobility of $\mathrm{NM}_{1}, \mathrm{C}_{o x}$ is the gate-oxide capacitance per unit area, $(W / L)_{1}$ is the ratio of width and length of $\mathrm{NM}_{1}$, and $K$ is the ratio of $\mathrm{NM}_{2}$ and $\mathrm{NM}_{1}$. The value of $I_{\text {out }}$ is set to $1 \mu \mathrm{A}$ to balance the power consumption and area. The length of $\mathrm{NM}_{1}$ is set to $2 \mu \mathrm{m}$ so that the channel length modulation effect can be reduced. The value of $K$ is set to 32 and resistance of $R_{1}$ is about $170 \mathrm{~K} \Omega$ by calculation. To avoid the degenerate state when the current is 0 , a start-up structure is introduced with isolated $\mathrm{NMOS} \mathrm{NM}_{3}-\mathrm{NM}_{4}$ and isolated PMOS $\mathrm{PM}_{3}-\mathrm{PM}_{4}$. When the bias current is 0 , the gate-source voltage $V_{\mathrm{GS} 2}$ of $\mathrm{NM}_{2}$ is $0 \mathrm{~V}$. At this time, the gate voltages of $\mathrm{PM}_{3}$ and $\mathrm{PM}_{4}$ are $0 \mathrm{~V}$, and they are turned on. Then, the gate of $\mathrm{NM}_{3}$ is pulled high and turned on, and there is current that flows through resistor $R_{1}$. Therefore, the bias current is not 0 , and the degenerate state is eliminated. Once there is flowing current, the gate-source voltage $V_{\mathrm{GS} 2}$ of $\mathrm{NM}_{2}$ increases to a value greater than the threshold voltage $V_{\mathrm{THN}}$, and then $\mathrm{NM}_{4}$ is turned on. Moreover, the gate voltage of $\mathrm{NM}_{3}$ is pulled down, and the start-up circuit is turned off.

\section{- Under-voltage detection circuit}

The under-voltage detection circuit is shown in the middle part of Figure 4, which is composed of isolated PMOS $\mathrm{PM}_{5}-\mathrm{PM}_{6}$, isolated NMOS $\mathrm{NM}_{5}-\mathrm{NM}_{7}$, resistors $R_{2}-R_{3}$, and a level shifter circuit. 
As the bootstrap voltage gradually increases from 0 , the bias current $I_{\text {out }}$ rises. $\mathrm{PM}_{5}$ mirrors the current of $\mathrm{PM}_{2}$, and the gate-source voltage $V_{\mathrm{GS} 5}$ of $\mathrm{PM}_{5}$ is equal to the $V_{\mathrm{GS} 2}$ of $\mathrm{PM}_{2}$. Due to the existence of $R_{3}$ and $\mathrm{PM}_{5}, \mathrm{NM}_{6}$ cannot be turned on immediately at a low current. At this time, the drain voltage of $\mathrm{PM}_{6}$ is pulled up to $V_{\text {boot }}$. After the first level shifter circuit, the output of the under-voltage signal $u v$ is $V_{\mathrm{DD}}$.

By adjusting the size of $\mathrm{PM}_{5}, \mathrm{NM}_{5}, R_{2}$, and $R_{3}$, the under-voltage threshold $V_{\mathrm{THL}}$ voltage can be set to $2.2 \mathrm{~V}$ to ensure a low on-resistance of the power NMOS. When the bootstrap voltage reaches $V_{\mathrm{THL}}$, which can be expressed as:

$$
V_{\mathrm{THL}}=V_{\mathrm{DSP} 5}+V_{\mathrm{GSN} 5}+I_{\mathrm{out}} \times\left(R_{2}+R_{3}\right)+V_{\mathrm{THN}}
$$

$\mathrm{NM}_{6}$ and $\mathrm{NM}_{7}$ are turned on, and the drain voltage of $\mathrm{NM}_{7}$ gradually decreases until it is lower than the threshold of the level shifter. At this time, the output of the under-voltage signal $u v$ is GND. In this case, $\mathrm{NM}_{5}$ is assumed to be critical saturation, and $V_{\mathrm{DSP} 5}$ could be set to the overdrive voltage (about $200 \mathrm{mV}$ to $300 \mathrm{mV}$ ). $V_{\mathrm{THN}}$ is about $900 \mathrm{mV}$, and $V_{\mathrm{GSN} 5}$ should be larger than threshold voltage. The above data are substituted in equation 2 , and then the value of $R_{2}$ and $R_{3}$ is estimated at about $200 \mathrm{~K} \Omega$.

- Over-voltage detection circuit

Isolated PMOS $\mathrm{PM}_{7}-\mathrm{PM}_{9}$, isolated $\mathrm{NMOS} \mathrm{NM}_{8}-\mathrm{NM}_{15}$, resistors $R_{4}-R_{5}$, Zener diode $\mathrm{DZ}$, and another level shifter circuit constitute an over-voltage detection circuit, as shown in the right part of Figure 4.

The gate voltage of $\mathrm{NM}_{9}$ is a fixed value when the bias current $I_{\text {out }}$ is determined, which is:

$$
V_{\mathrm{GN} 9}=I_{\mathrm{out}} \times R_{4}+V_{\mathrm{GSN} 8}
$$

The source voltage of $\mathrm{NM}_{9}$ is:

$$
V_{\mathrm{SN} 9}=V_{\mathrm{boot}}-\left(V_{\mathrm{GSN} 10}+V_{\mathrm{GSN} 11}+V_{\mathrm{GSN} 12}+V_{\mathrm{GSN} 13}+V_{\mathrm{GSN} 14}\right)=V_{\mathrm{boot}}-5 \times V_{\mathrm{GSN}}
$$

Therefore, the gate-source voltage of $\mathrm{NM}_{9}$ is:

$$
V_{\mathrm{GSN} 9}=I_{\mathrm{out}} \times R_{4}+V_{\mathrm{GSN} 8}+5 \times V_{\mathrm{GSN}}-V_{\mathrm{boot}}
$$

When the gate-source voltage of $\mathrm{NM}_{9}$ is lower than $V_{\mathrm{THN}}, \mathrm{NM}_{9}$ will be turned off, and the gate voltage of $\mathrm{NM}_{15}$ will be pulled up to $V_{\text {boot }}$, while the drain voltage will be pulled low. Therefore, the output of _ov signal is GND after the level shifter circuit. Therefore, the over-voltage threshold is deduced as:

$$
V_{\mathrm{THH}}=I_{\mathrm{out}} R_{4}+5 \times V_{\mathrm{GSN}}+V_{\mathrm{GS} 8}-V_{\mathrm{THN}}
$$

However, there is another device, a Zener diode DZ, used in the over-voltage circuit, which double guarantees_ov signal to be low during its over-voltage. DZ will clamp the source voltage of $\mathrm{NM}_{9}$ through providing enough current when the bootstrap voltage reaches its threshold. At this time, the threshold voltage is:

$$
V_{\mathrm{THH}}^{\prime}=V_{\mathrm{DZ}}+I_{\mathrm{out}} R_{4}
$$

where $V_{\mathrm{DZ}}$ is the clamp voltage of Zener diode.

The constant current of this circuit is set to $1 \mu \mathrm{A}$ each branch, and the size of $\mathrm{PM}_{7}$ and $\mathrm{PM}_{8}$ is the same as $\mathrm{PM}_{1}$ and $\mathrm{PM}_{2}$. By adjusting the size of $\mathrm{NM}_{8}, \mathrm{NM}_{10}-\mathrm{NM}_{14}$, and $R_{4}$, the $V_{\text {THH }}$ voltage is set to $6 \mathrm{~V}$, thereby avoiding the breakdown of the power NMOS.

The TBDC circuit is designed with fully isolated devices due to area consideration, and the bootstrap capacitor is directly charged from the BUS voltage with the DCBV circuit, which can be used for higher frequency. Due to the usage of a digital control method, the bootstrap voltage is stable when $V_{\mathrm{IN}}$ varies from $6 \mathrm{~V}$ to $48 \mathrm{~V}$; therefore, the line regulation of this circuit can be considered close to 0 . 


\subsubsection{Level Shifters}

There are two types of level shifters employed in the proposed bootstrap structure. One is a level-up shifter used to control the power NMOS, and the other is a level-down shifter in the TBDC circuit.

- $\quad$ Level-up shifter

The pwo_in signal is the output of control logic, and it is $3.3 \mathrm{~V}$ or $5 \mathrm{~V}$ relative to ground, which is not suitable to control the driver directly. Therefore, the level-up shifter is adopted to shift the voltage relative to ground to the voltage relative to $V_{\mathrm{SW}}$. The level-up shifter used in the proposed structure is illustrated in Figure 5a. HPM $, \mathrm{HPM}_{2}, \mathrm{HNM}_{1}$, and $\mathrm{HNM}_{2}$ are the only high-voltage devices in this circuit, and other devices are low-voltage devices (INV1) or isolated devices ( $\mathrm{PM}_{11}, \mathrm{PM}_{12}$ and INV2). $\mathrm{R}_{7}$ is a pull-up resistor to ensure the initial condition of $h h_{-} i$, preventing from floating gate of INV2.

- Level-down shifter

A level-down shifter is used in the TBDC circuit to shift the $u v$ and $\_o v$ signal from floating voltage to voltage relative to ground, so that $u v$ can be an input of control logic and $\_v$ is appropriate for controlling NM in the DCBV. The principle of the level-down shifter is similar to that of the level-up shifter, and the circuit is shown in Figure 5b.

\subsubsection{Driver}

The driver circuit shown in Figure 6 provides sufficient driving current for the power device through $\mathrm{PM}_{10}$ and $\mathrm{NM}_{16}$. The source and sink current are determined by the gate capacitance $C_{\mathrm{GS}}$ of the power device, turn-on/off voltage of the power device and required rising/falling time, and can be adjusted by changing the size of $\mathrm{PM}_{10}$ and $\mathrm{NM}_{16}$. Deadtime is used to prevent the power rail from shooting through, and the waveforms of $h s \_i n$, gate of $\mathrm{PM}_{10}$, and $\mathrm{NM}_{16}$ are also shown in Figure 6.

\section{Results}

The circuit is implemented by the CSMC $0.25 \mu \mathrm{m} 60 \mathrm{~V}$ BCD process. Figure 7 shows the micrograph and testbench photos using the proposed bootstrap structure. The chip area is $1.4 \times 1.3 \mathrm{~mm}^{2}$, of which the bootstrap circuit only occupies $0.149 \mathrm{~mm}^{2}$. The maximum input voltage can be up to $48 \mathrm{~V}$, and the operating frequency can reach $5 \mathrm{MHz}$.

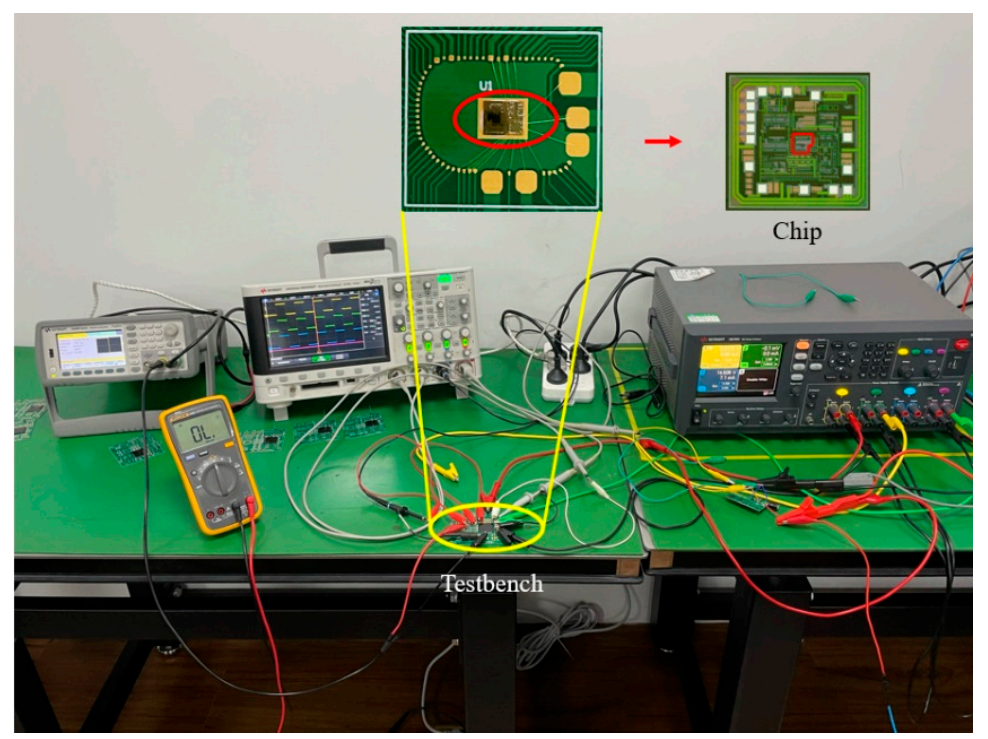

Figure 7. Chip micrograph and testbench of the buck converter with the proposed bootstrap circuit. 


\subsection{Simulation Results}

Figure 8 shows the DC simulation result of the TBDC circuit. When the bootstrap voltage is lower than $V_{\mathrm{THL}}(2.101 \mathrm{~V}), u v$ and _ov are high. When the voltage is between the $V_{\text {THL }}$ and $V_{\text {THH }}(2.101-6.099 \mathrm{~V})$, the $u v$ output is low and the $\_o v$ output is high. When the voltage between $V_{\text {boot }}$ and $V_{\mathrm{SW}}$ is higher than the $V_{\mathrm{THH}}(6.099 \mathrm{~V})$, the $u v$ output is low and the _ov output is low.

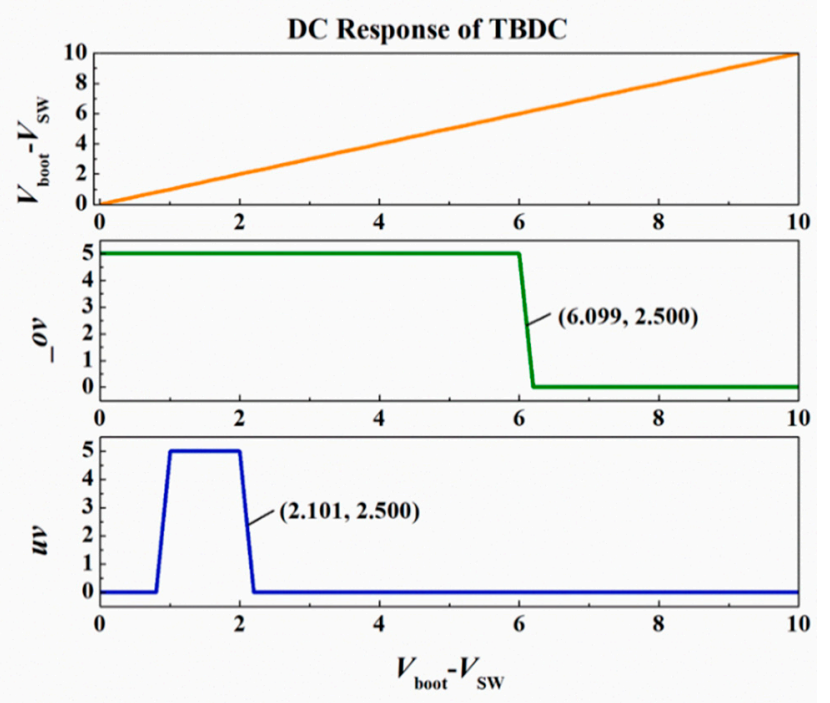

Figure 8. Simulated DC under-voltage and over-voltage threshold of TBDC.

The overall and enlarged simulation results are shown in Figure $9 \mathrm{a}, \mathrm{b}$. When the pwm is 0 and the bootstrap voltage is higher than $\mathrm{V}_{\mathrm{THH}}(6 \mathrm{~V})$, the output of the $\_0 v$ signal is $0 \mathrm{~V}$ and NM is turned off. Therefore, there is no voltage drop on the bias resistor $R_{\mathrm{b}}$, and the voltage of $V_{\mathrm{SGP}}$ is $0 \mathrm{~V}$, which causes the charging path to be turned off. When the bootstrap voltage is lower than $\mathrm{V}_{\mathrm{THH}}$, the output of the _ov signal is $5 \mathrm{~V}$ and NM is turned on. A voltage drop can be formed on the bias resistor $R_{\mathrm{b}}$, and the voltage of $V_{\mathrm{SGP}}$ can increase to $3 \mathrm{~V}$, causing the charging path to be opened. However, the voltage of $V_{\mathrm{SGP}}$ only increases to $3 \mathrm{~V}$ instead of $5 \mathrm{~V}$, which can be attributed to the fact that the bootstrap voltage is quickly charged to $6 \mathrm{~V}$ by the $V_{\mathrm{IN}}$ when the PM is turned on. During this period, the ripple of $V_{\text {boot }}-V_{\text {SW }}$ is only $1.583 \mathrm{mV}$.

The temperature simulation result is shown in Figure 10a. The minimum bootstrap voltage is $5.866 \mathrm{~V}$ at $-40{ }^{\circ} \mathrm{C}$, and the maximum bootstrap voltage is $6.210 \mathrm{~V}$ at $120^{\circ} \mathrm{C}$. The bootstrap voltage is positively correlated with the temperature, and the temperature coefficient is calculated as:

$$
\mathrm{TC}=\frac{\Delta V_{\text {out }}}{\left(T_{\max }-T_{\text {min }}\right) \times V_{\text {nom }}} \times 10^{6}=348 \mathrm{ppm} /{ }^{\circ} \mathrm{C}
$$

The simulation results for different load currents are shown in Figure 10b, indicating a good load regulation. The maximum bootstrap voltage is $6.210 \mathrm{~V}$ at $1 \mathrm{~A}$, and the minimum voltage is $6.208 \mathrm{~V}$ at $1 \mathrm{~mA}$. The load regulation $S_{v}$ can be calculated as:

$$
S_{v}=\frac{\Delta V_{\text {out }}}{V_{\text {nom }} \times \Delta I_{\text {out }}}=0.03 \% / \mathrm{mA}
$$

The simulated result of the buck converter at $I_{\text {load }}=1$ A configured by this bootstrap structure is shown in Figure 11. The input and output voltages are $14.5 \mathrm{~V}$ and $5 \mathrm{~V}$, respectively. The ripple of the output voltage is $2.612 \mathrm{mV}$ with an efficiency of $92.7 \%$. The highest simulated efficiency is $94.87 \%$ at $600 \mathrm{~mA}$. 


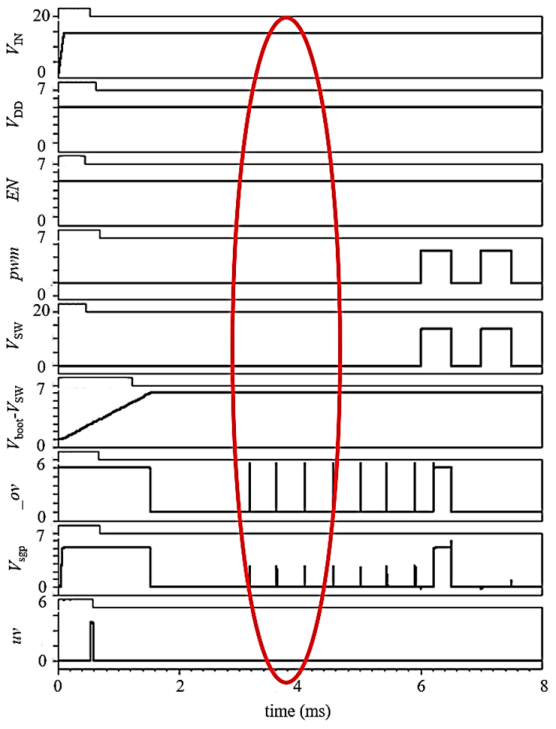

(a)

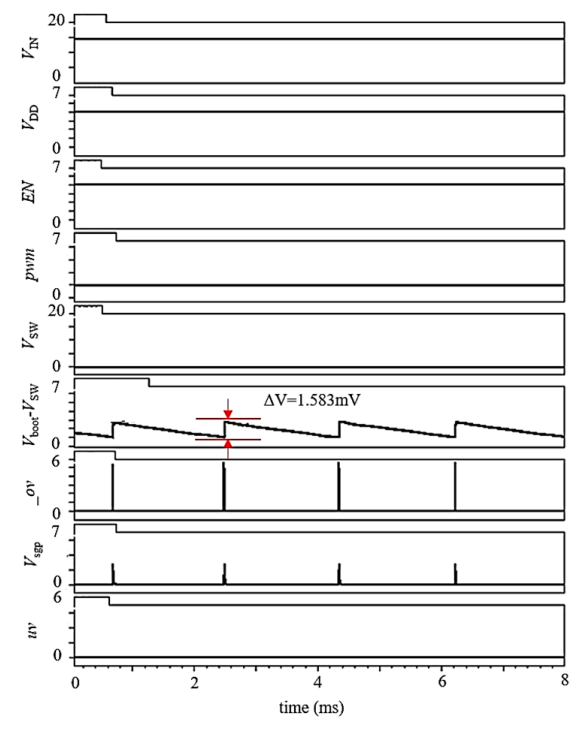

(b)

Figure 9. Simulated results of the proposed bootstrap structure: (a) overall result and (b) enlarged result.

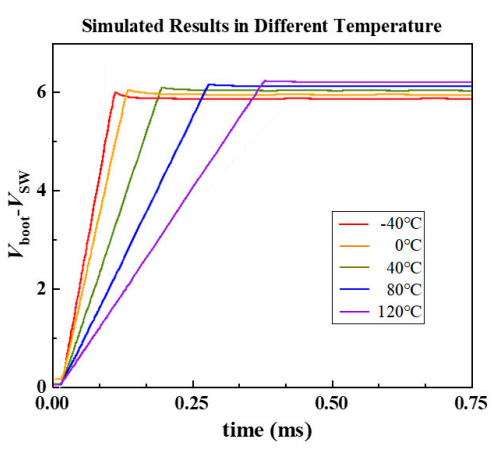

(a)

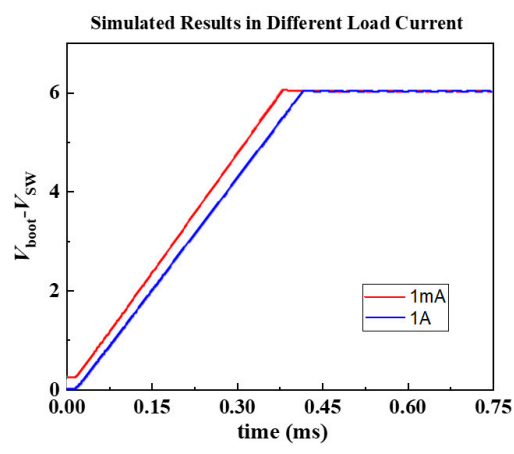

(b)

Figure 10. Simulation result at (a) different temperature $\left(\mathrm{T}=-40^{\circ} \mathrm{C}, 0^{\circ} \mathrm{C}, 40^{\circ} \mathrm{C}, 80^{\circ} \mathrm{C}\right.$ and $\left.120^{\circ} \mathrm{C}\right)$ and (b) different load current $(1 \mu \mathrm{A}$ and $1 \mathrm{~mA})$.

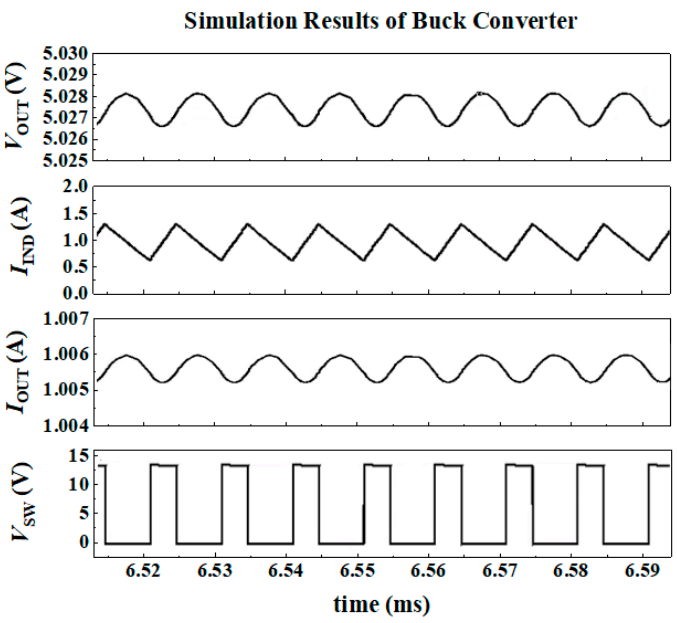

Figure 11. Simulation results of buck converter $\left(V_{\mathrm{IN}}=14.5 \mathrm{~V}, V_{\mathrm{OUT}}=5 \mathrm{~V}, I_{\mathrm{load}}=1 \mathrm{~A}\right)$. 


\subsection{Test Results}

The test result, as shown in Figure 12a, indicates that the voltage power-up time of bootstrap voltage is approximately $170 \mu \mathrm{s}$, and the stable voltage is approximately $6 \mathrm{~V}$, which are consistent with the simulation result. The results of different operation frequencies are shown in Figure 12b, indicating good support over a wide frequency range.

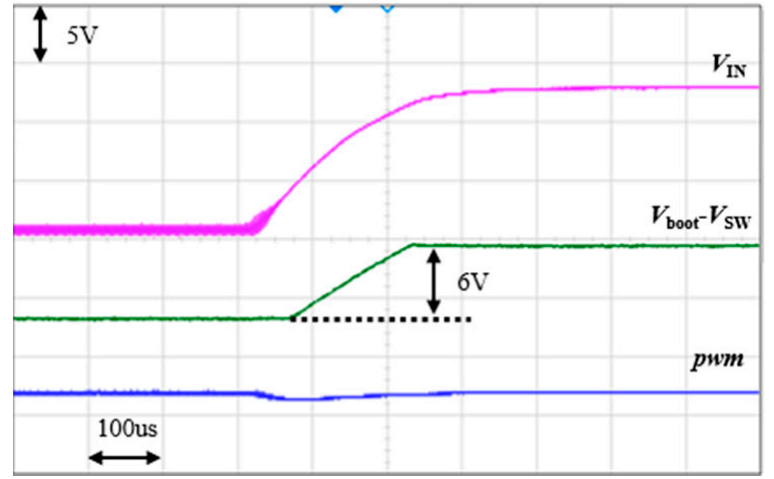

(a)

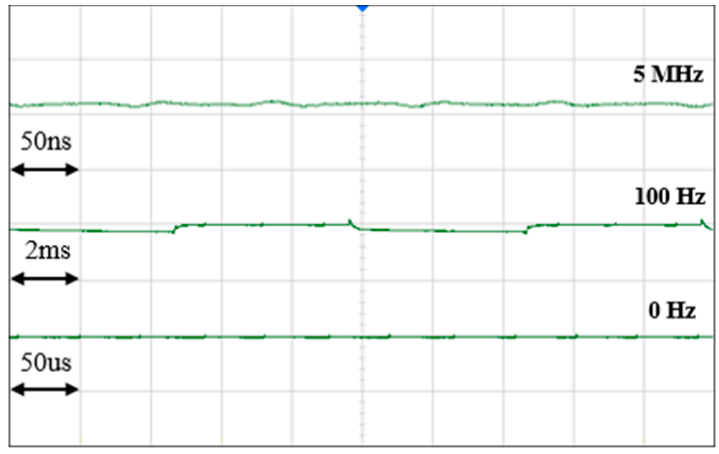

(b)

Figure 12. Measured bootstrap circuit (external $\left.C_{\text {boot }}=1 \mu \mathrm{F}\right)(\mathbf{a})$ power on and stable state, and (b) bootstrap voltage at pwm $=0 \mathrm{~Hz}, 1 \mathrm{MHz}$, and $5 \mathrm{MHz}$.

A comparison of the simulation and actual measurement results of the buck converter are shown in Figure 13. Under the following conditions, $V_{\mathrm{IN}}=14.5 \mathrm{~V}$ and $V_{\mathrm{OUT}}=5 \mathrm{~V}$, the highest tested efficiency of the circuit is $83.6 \%\left(I_{\text {load }}=400 \mathrm{~mA}\right)$. The figure-of-merit $(\mathrm{FOM})$ is defined as:

$$
\mathrm{FOM}=\frac{\mathrm{A}}{I_{\text {load,max }} \times \eta^{0.5}}
$$

where $\mathrm{A}$ is the silicon area, $I_{\text {load,max }}$ is the maximum load, and $\eta$ is the efficiency at maximum load [31]. For this definition, a low value indicates a better performance and the circuit achieves a good FOM of 0.074. Due to diode conduction loss, MOS conduction loss, and MOS switching loss, there is a certain gap between the simulation results and the actual measurement results.

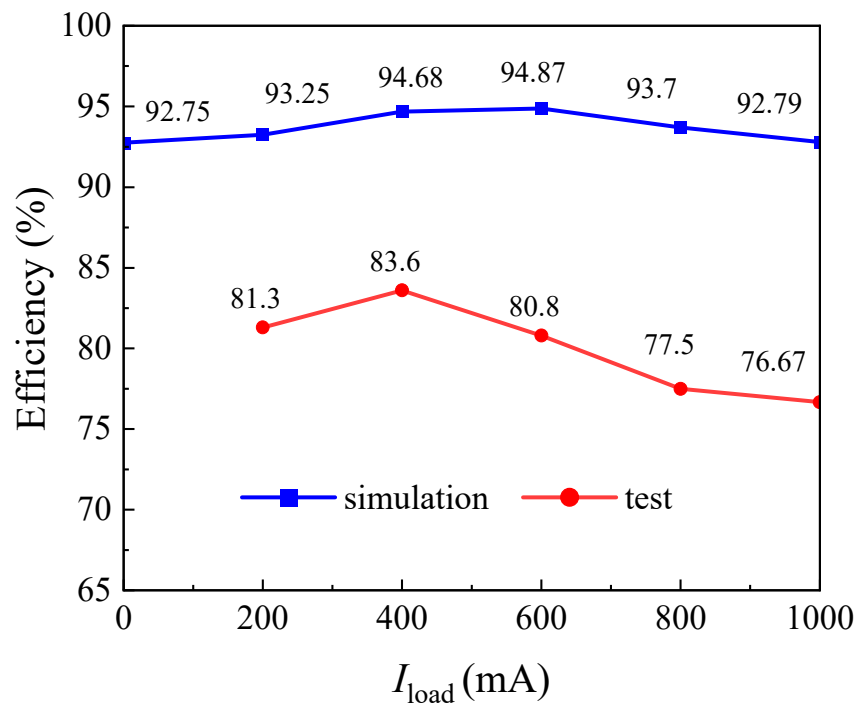

Figure 13. Comparison between the simulated and test results of the buck converter efficiency at different currents $\left(V_{\mathrm{IN}}=14.5 \mathrm{~V}, V_{\mathrm{OUT}}=5 \mathrm{~V}\right)$. 


\section{Discussion}

Table 1 shows the comparison results between the structure designed in this paper and those reported in previous literature. Compared with the previous research, this work has the advantages of a wider input voltage from $3.6 \mathrm{~V}$ to $48 \mathrm{~V}$, higher switching frequency up to $5 \mathrm{MHz}$, larger output current of $2.7 \mathrm{~A}$, and a smaller chip area of $1.82 \mathrm{~mm}^{2}$ with a good FOM of 0.074 while maintaining the same efficiency. With the digital control method being different from previous research, the simulation and test result implicate that the novel DCBV and TBDC methods in the proposed bootstrap structure is feasible and stable. The proposed circuit can be applied to some power areas such as dc-dc converters.

Table 1. Comparison with previously published works is shown, indicating wider input voltage, higher switching frequency, larger output current, and smaller chip area with a good FOM while maintaining the same efficiency.

\begin{tabular}{|c|c|c|c|c|}
\hline Parameter & This Work & $\operatorname{Ref}[23]$ & $\operatorname{Ref}[32]$ & Ref [22] \\
\hline $\begin{array}{l}\text { Technology } \\
(\mu \mathrm{m})\end{array}$ & $\begin{array}{c}0.25 \mu \mathrm{m} 60 \mathrm{~V} \\
\mathrm{BCD}\end{array}$ & $\begin{array}{c}0.35 \mu \mathrm{m} 40 \mathrm{~V} \\
\text { CMOS }\end{array}$ & $\begin{array}{c}0.18 \mu \mathrm{m} \text { HV } \\
\text { BiCMOS }\end{array}$ & $\begin{array}{c}0.35 \mu \mathrm{m} \mathrm{HV} \\
\text { BCD }\end{array}$ \\
\hline $\begin{array}{l}\text { Input voltage } \\
V_{\mathrm{IN}}(\mathrm{V})\end{array}$ & $3.6-48$ & $3.6-36$ & 15 & $3-40$ \\
\hline $\begin{array}{c}\text { Switching } \\
\text { frequency }(\mathrm{MHz})\end{array}$ & $0.1-5$ & $0.2-2.4$ & 2 & $10-30$ \\
\hline Output current (A) & 2.7 & 2 & 2.6 & 1.2 \\
\hline Efficiency $\eta(\%)$ & 83.6 & 85.98 & $\mathrm{~N} / \mathrm{A}$ & $\mathrm{N} / \mathrm{A}$ \\
\hline Chip area $\mathrm{A}\left(\mathrm{mm}^{2}\right)$ & 1.82 & 4.78 & $\mathrm{~N} / \mathrm{A}$ & $\mathrm{N} / \mathrm{A}$ \\
\hline Bootstrap circuit area $\left(\mathrm{mm}^{2}\right)$ & 0.149 & 0.062 & 0.42 & 0.48 \\
\hline Dropout voltage (mV) & $\begin{array}{c}1.583 \\
\text { (simulation) }\end{array}$ & $\begin{array}{c}4.6 \\
\text { (simulation) }\end{array}$ & $\mathrm{N} / \mathrm{A}$ & $\mathrm{N} / \mathrm{A}$ \\
\hline LDO type & Capless & Capless & External cap & $\mathrm{N} / \mathrm{A}$ \\
\hline $\operatorname{FOM}\left(\mathrm{A} / I_{\text {load }, \max } \times \eta^{0.5}\right)$ & 0.074 & 0.258 & $\mathrm{~N} / \mathrm{A}$ & $\mathrm{N} / \mathrm{A}$ \\
\hline $\begin{array}{l}\text { Bootstrap rail } \\
\text { control }\end{array}$ & TBDC & DVS & $\mathrm{N} / \mathrm{A}$ & $\mathrm{ABB}$ \\
\hline
\end{tabular}

However, due to the lack of research on temperature compensation, the temperature coefficient of this structure is not as low as traditional LDOs. Therefore, future research on this circuit include decreasing the temperature coefficient and scaling higher power.

\section{Conclusions}

Bootstrap is a key structure for driving and protecting a high-side N-type power device. In this paper, a novel bootstrap circuit has been proposed, which is directly charged by the BUS voltage and employs a digital method to achieve a stable output. With an area of $1.82 \mathrm{~mm}^{2}$, this structure exhibits strict voltage control in a wide range of input voltages and frequencies. It is found that when using the dc-dc asynchronous buck converter, the maximum efficiency of the protype is $83.6 \%$, and the FOM is 0.074 , showing its future potential in a wide range of scenarios, such as in power converters, motor drivers, and automobiles.

Author Contributions: Conceptualization, Y.G. and F.Y.; methodology, Y.G. and F.Y.; software, Y.G., Y.C., and Y.K.; validation, Y.G., F.Y., and X.Z.; formal analysis, Y.G. and Y.C.; investigation, Y.G. and Y.K.; resources, X.Z.; data curation, Y.G.; supervision, F.Y. and X.Z.; writing-original draft preparation, Y.G.; writing - review and editing, Y.G. and F.Y.; project administration, F.Y. and X.Z.; funding acquisition, X.Z. All authors have read and agreed to the published version of the manuscript.

Funding: This research was supported by the Science and Technology Service Network Initiative of CAS (No. KFJ-STS-QYZX-099).

Acknowledgments: I would like to thank Huan Wang, Shuo Wang, Libo Zhang, and Kun Lin at Advanced Semiconductors of Intelligences and Technologies, Haining, China for helping in the wire bonding and chip test. 
Conflicts of Interest: The authors declare no conflict of interest.

\section{References}

1. Weckbrodt, J.; Ginot, N.; Batard, C.; Le, T.L.; Azzopardi, S. A Bidirectional Communicating Power Supply Circuit for Smart Gate Driver Boards. IEEE Trans. Power Electron. 2020, 35, 8540-8549. [CrossRef]

2. Zhang, Y.; Rodriguez, M.; Maksimovic, D. Very High Frequency PWM Buck Converters Using Monolithic GaN Half-Bridge Power Stages with Integrated Gate Drivers. IEEE Trans. Power Electron. 2016, 31, 7926-7942. [CrossRef]

3. Ye, Z.C.; Lei, Y.T.; Liu, W.-C.; Shenoy, P.S.; Pilawa-Podgurski, R.C.N. Improved Bootstrap Methods for Powering Floating Gate Drivers of Flying Capacitor Multilevel Converters and Hybrid Switched-Capacitor Converters. IEEE Trans. Power Electron. 2019, 35, 5965-5977. [CrossRef]

4. Nguyen, V.-S.; Lefranc, P.; Crebier, J.-C. Gate Driver Supply Architectures for Common Mode Conducted EMI Reduction in Series Connection of Multiple Power Devices. IEEE Trans. Power Electron. 2018, 33, 10265-10276. [CrossRef]

5. Ranganathan, S.; Mohan, A.N.D. Formulation and Analysis of Single Switch High Gain Hybrid DC to DC Converter for High Power Applications. Electronics 2021, 10, 2445. [CrossRef]

6. Garza-Arias, E.; Rosas-Caro, J.C.; Valdez-Resendiz, J.E.; Mayo-Maldonado, J.C.; Escobar-Valderrama, G.; Guillen, D.; Rodríguez, A. The Fourth-Order Single-Switch Improved Super-Boost Converter with Reduced Input Current Ripple. Electronics 2021, 10, 2379. [CrossRef]

7. Aksin, D.; Al-Shyoukh, M.A.; Maloberti, F. A bootstrapped switch for precise sampling of inputs with signa range beyond supply voltage. In Proceedings of the IEEE 2005 Custom Integrated Circuits Conference (CICC 2005), San Jose, CA, USA, 21 September 2005

8. Lima, J.A.D.; Pimenta, W.A. A current-mode active clampling for boostrap circuit applied to DC/DC buck converters. In Proceedings of the 2009 IEEE International Symposium on Circuits and Systems (ISCAS 2009), Taipei, Taiwan, $24-27$ May 2009.

9. Zhou, Z.; Ming, X.; Zhang, B.; Li, Z. Design of Novel Bootstrap Driver Used in High Power BUCK Converter. In Proceedings of the 2009 IEEE 8th International Conference on ASIC (ASICON 2009), Changsha, China, 20-23 October 2009.

10. Mudanai, S.; Chindalore, G.; Shih, W.-K.; Wang, H.; Tasch, A.F., Jr.; Mazar., C.M. Temperature characterization and modeling of electron and hole mobilities in MOS accumulation layers. In Proceedings of the 56th Annual Device Research Conference Diges (DRC, 1998), Charlottesville, VA, USA, 22-24 June 1998; pp. 20-21.

11. Seo, D.W.; Choi, H.G.; Twynam, J.; Kim, K.M.; Yim, J.S.; Moon, S.-W.; Jung, S.; Lee, J.; Roh, S.D. 600 V-18 A GaN Power MOS-HEMTs on $150 \mathrm{~mm}$ Si Substrates with Au-Free Electrodes. IEEE Electron. Device Lett. 2014, 35, 446-448. [CrossRef]

12. Kanamura, M.; Ohki, T.; Kikkawa, T.; Imanishi, K.; Imada, T.; Yamada, A.; Hara, N. Enhancement-Mode GaN MIS-HEMTs with n-GaN/i-AlN/n-GaN Triple Cap Layer and High- \$k\$ Gate Dielectrics. IEEE Electron. Device Lett. 2010, 31, 189-191. [CrossRef]

13. Zheng, J.X.; Ma, X.H.; Lu, Y.; Zhao, B.C.; Zhang, H.S.; Zhang, M.; Hao, Y. A Scalable Active Compensatory Sub-Circuit for Accurate GaN HEMT Large Signal Models. IEEE Microw. Wirel. Compon. Lett. 2016, 26, 431-433. [CrossRef]

14. Rossetto, I.; Meneghini, M.; Hilt, O.; Bahat-Treidel, E.; De Santi, C.; Dalcanale, S.; Wuerfl, J.; Zanoni, E.; Meneghesso, G. Time-Dependent Failure of GaN-on-Si Power HEMTs with p-GaN Gate. IEEE Trans. Electron. Devices 2016, 63, 2334-2339. [CrossRef]

15. Huang, M.; Lu, Y.; Martins, R.P. Review of Analog-Assisted-Digital and Digital-Assisted-Analog Low Dropout Regulators. IEEE Trans. Circuits Syst. II Express Briefs 2021, 68, 24-29. [CrossRef]

16. Ballo, A.; Grasso, A.D.; Palumbo, G. A simple and effective design strategy to increase power conversion efficiency of linear charge pumps. Int. J. Circuit Theory Appl. 2019, 48, 157-161. [CrossRef]

17. Ballo, A.; Grasso, A.D.; Palumbo, G.; Tanzawa, T. Linear distribution of capacitance in Dickson charge pumps to reduce rise time. Int. J. Circuit Theory Appl. 2020, 48, 555-566. [CrossRef]

18. Ballo, A.; Grasso, A.D.; Palumbo, G. Current-mode body-biased switch to increase performance of linear charge pumps. Int. J. Circuit Theory Appl. 2020, 48, 1864-1872. [CrossRef]

19. Grobe, J.; Hanhart, M.; Maul, F.; Weihs, L.; Rolff, L.; Wunderlich, R.; Heinen, S. Design of a Flexible Bandgap Based High Voltage UVLO with Pre-Regulator. In Proceedings of the 2020 27th IEEE International Conference on Electronics, Circuits and Systems (ICECS 2020), Glasgow, UK, 23-25 November 2020.

20. Park, S.; Jahns, T.M. A self-boost charge pump topology for a gate drive high-side power supply. IEEE Trans. Power Electron. 2005, 20, 300-307. [CrossRef]

21. Xin, Z.; Zhigang, L.; Huang, A. A High-Dynamic Range Current Source Gate Driver for Switching-Loss Reduction of High-Side Switch in Buck Converter. IEEE Trans. Power Electron. 2010, 25, 1439-1443.

22. Yuan, B.; Ying, J.; Ng, W.T.; Lai, X.-Q.; Zhang, L.-F. A High-Voltage DC-DC Buck Converter with Dynamic Level Shifter for Bootstrapped High-Side Gate Driver and Diode Emulator. IEEE Trans. Power Electron. 2020, 35, 7295-7304. [CrossRef]

23. Kong, M.; Yan, W.; Li, W. Design of a synchronous-rectified buck bootstrap MOSFET driver for voltage regulator module. In Proceedings of the 2007 7th International Conference on ASIC (ASICON 2007), Guilin, China, 22-25 October 2007.

24. Abe, K.; Nishijima, K.; Harada, K.; Nakano, T.; Nabeshima, T.; Sato, T. A Novel Three-Phase Buck Converter with Bootstrap Driver Circuit. In Proceedings of the 2007 IEEE Power Electronics Specialists Conference (PESC 2007), Orlando, FL, USA, 17-21 June 2007. 
25. Yuan, B.; Xiao, L.-Q.; Wang, B.-Y.; Ying, J. High-Speed Dynamic Level Shifter for High-Side Bootstrapped Gate Driver in High-Voltage Buck Regulators. IEEE Trans. Circuits Syst. II Express Briefs 2021, 68, 3083-3087. [CrossRef]

26. Li, S.T.; Wang, P.Y.; Chen, C.J.; Hsu, C.C. A $10 \mathrm{MHz}$ GaN Driver with Gate Ringing Suppression and Active Bootstrap Control. In Proceedings of the 2019 IEEE Workshop on Wide Bandgap Power Devices and Applications in Asia (WiPDA Asia), Taipei, Taiwan, 23-25 May 2019.

27. Ke, X.; Sankman, J.; Song, M.K.; Forghani, P. 16.8 A 3-to-40V 10-to-30MHz automotive-use GaN driver with active BST balancing and VSW dual-edge dead-time modulation achieving 8.3 improvement and 3.4ns constant propagation delay. In Proceedings of the IEEE International Solid-State Circuits Conference, San Francisco, CA, USA, 31 January-4 February 2016.

28. Ming, X.; Fan, Z.; Xin, Y.; Zhang, X.; Shi, F.; Pan, S.; Zhang, J.; Wang, Z.; Zhang, B. An Advanced Bootstrap Circuit for High Frequency, High Area-Efficiency and Low EMI Buck Converter. IEEE Trans. Circuits Syst. II Express Briefs 2019, 66, 858-862. [CrossRef]

29. Liu, Y.; Liu, S.; Ye, Q.; Yuan, B.; Lai, X. A feedback loop regulated bootstrap driver circuit with improved drive capability for high voltage buck DC-DC converter. Microelectron. J. 2013, 44, 1290-1295. [CrossRef]

30. Razavi, B. Bandgap Reference. In Dsign of Analog CMOS Integrated Circuits, 2nd ed.; McGraw-Hill: New York, NY, USA, 2017; pp. 510-512.

31. Chen, W.-C.; Chou, Y.-W.; Chien, M.-W.; Chen, H.-C.; Yang, S.-H.; Chen, K.-H.; Lin, Y.-H.; Lee, C.-C.; Lin, S.-R.; Tsai, T.-Y. A Dynamic Bootstrap Voltage Technique for a High-Efficiency Buck Converter in a Universal Serial Bus Power Delivery Device. IEEE Trans. Power Electron. 2016, 31, 3002-3015. [CrossRef]

32. Seidel, A.; Costa, M.S.; Joos, J.; Wicht, B. Area Efficient Integrated Gate Drivers Based on High-Voltage Charge Storing. IEEE J. Solid-State Circuits 2015, 50, 1550-1559. [CrossRef] 